\title{
Characteristics of PBMC obtained from leukapheresis products and tumor biopsies of patients with non-small cell lung cancer
}

\author{
JOHN R. YANNELLI ${ }^{1}$, JO A. TUCKER ${ }^{1}$, GIOVANNA HIDALGO ${ }^{1}$, SARA PERKINS ${ }^{1}$, \\ RICHARD KRYSCIO ${ }^{2}$ and EDWARD A. HIRSCHOWITZ ${ }^{3}$
}

Departments of ${ }^{1}$ Microbiology Immunology and Molecular Genetics, ${ }^{2}$ Biostatistics and ${ }^{3}$ Internal Medicine, School of Medicine, University of Kentucky, Lexington, KY 40536-0093, USA

Received May 13, 2009; Accepted July 9, 2009

DOI: $10.3892 /$ or_00000588

\begin{abstract}
The current study characterized peripheral blood mononuclear cells (PBMC) obtained from leukapheresis products of patients with non-small cell lung cancer (NSCLC) for cytokine release, the ability to incorporate tritiated thymidine following stimulation using PHA as well as the levels of both CD4 and CD8 regulatory T cells (Tregs) as defined by FoxP3 expression. Results were compared to normal donor PBMC obtained from buffy coat products. Heterogeneous levels of Th1 ( $\gamma$ interferon and IL-2), Th2 (IL-10 and IL-13), pro-inflammatory (TNF- $\alpha$ and IL-6) and the hematopoietic inducing cytokine GMCSF were detected from both populations of PBMC as measured using ELISA. Overall, we observed that combined levels of Th1 and Th2 cytokines were higher in lung cancer patients compared to that seen in normal donor PBMC. The increased cytokine production was coupled with an observed decrease in the ability of lung cancer patient PBMC to incorporate tritiated thymidine. Furthermore, cytokine containing supernatants obtained from patients inhibited the incorporation of tritiated thymidine from PBMC obtained from normal donors. Thus, the combined cytokines which included high levels of IL-10, appeared to exhibit suppressive functional activity. While not statistically significant, the overall trend toward a Th2 cytokine environment was supported by an increased level of Tregs observed in the leukapheresis products of lung cancer patients. These levels were variable and were accompanied by higher than normal levels of $\mathrm{CD} 8^{+}$cells co-expressing FoxP3. Finally, tumor biopsies were examined from lung cancer patients along with autologous normal adjacent tissue (NAT). In these studies, both $\gamma$ interferon and IL-10 were detected. The levels of IL-10 in the LPS stimulated cultures were statistically greater from the cancer biopsies compared
\end{abstract}

Correspondence to: Dr John R. Yannelli, University of Kentucky, Markey Cancer Center, Room 312 Combs Building, 800 Rose Street, Lexington, KY 40536-0093, USA

E-mail: jyann1@email.uky.edu

Key words: immunotherapy, peripheral blood mononuclear cells, cytokine, Treg, vaccine, Th1, Th2 to the NAT. The current study confirms many earlier results in a comprehensive manner and extends the analysis to leukapheresis products. An environment is described in cancer patients which is characterized by increased cytokine production and decreased proliferative potential likely under the influence of a significant population of regulatory $\mathrm{T}$ cells (Tregs). Taken together, these results are discussed as they relate to the potential implications in lung cancer patients immune response to their disease.

\section{Introduction}

Lung cancer is the leading cause of death due to cancer in both men and women $(1,2)$. Of these cases of lung cancer, approximately $80 \%$ are non-small lung cancer (NSCLC) (1). When diagnosed, the disease is often at an advanced stage and difficult to treat. The accepted therapy for NSCLC depends upon the stage in which the patients present (3). The treatments include: surgery for early-diagnosed and localized disease; radiation therapy for residual disease in the surgical field as well as un-resectable lesions; and/or chemotherapy for systemic and micro-metastatic disease. Unfortunately, 5 -year survival following these conventional approaches still remains low, estimated in the range of 5-20\% $(4,5)$.

As is the case with most forms of cancer, NSCLC tumors initiate and progress despite potential for the development of both innate and acquired anti-tumor immune responses. Tumor antigen specific cytotoxic T lymphocytes (CTL) $(6,7)$ and antibodies $(8,9)$ have been described and their anti-tumor activities well documented. However, these anti-tumor effector mechanisms are regulated and many times limited in their effectiveness by two types of suppressor cells. A lymphoid component, regulatory T cells (Tregs) (10-12) and a myeloid component, the myeloid derived suppressor cell (MDSC) (13). These cell types are operational in both afferent and efferent phases of immune responses. Suppressor activity is mediated through either direct cell contact or the release of cytokines such as IL-10 and TGF- $\beta$. Combinations of these and other cytokines, released by immune effector cells, connective tissue cells and tumor cells, condition the microenvironment and promote or inhibit the development of an effective anti-tumor immune response. 
Cytokines, the soluble mediators of immunity, were grouped by Mosmann et al (14), into two types, T helper 1 and $\mathrm{T}$ helper 2 , whose activity correlated with responses to different microbiologic infection (15). Th1 responses are characterized by $\gamma$ interferon release from $\mathrm{T}$ cells when challenged with intracellular pathogens including viruses and some bacteria. Th2 responses are characterized by IL-4 release effective against extracellular bacteria and parasites. Recently a family of T helper 17 (Th17) cytokines (16) were described and are important in responses to extracellular pathogens and in the induction of inflammation (17). Interestingly, Th1 and Th2 cytokines such as $\gamma$ interferon and IL-4 respectively can inhibit each other's action $(18,19)$. A typical example is the inhibition of Th2 or humoral responses by Th1 cytokines and the subsequent inhibition of Th1 or cell mediated immune (CMI) responses by Th2 cytokines. Thus an inherent balance is built into the system preventing overresponsiveness to both intra- and extracellular organisms. In the response to tumors, where Th1 or CMI responses are crucial, studies using ELISA or flow cytometric analysis of intracellular cytokines have demonstrated that PBMC from cancer patients release the Th2 cytokines IL- 4 and IL-10 preferentially when compared to PBMC obtained from normal donors (20-22). Thus, the suggestion has been that the microenvironment conditioned by these cytokines is inhibitory to effective Th1 anti-tumor responses.

The present study was done to compare the cytokine environment conditioned by PBMC obtained from leukapheresis products of patients with NSCLC. Twenty-nine NSCLC patients included in a dendritic cell (DC) vaccine trial performed by our group were chosen for analysis $(23,24)$. PBMC of these patients were compared to PBMC obtained from 10-normal donor buffy coats. The PBMC were analyzed for cytokine release to both $\mathrm{T}$ cell and $\mathrm{CD} 14^{+}$cell stimuli. Overall, the levels of cytokines secreted from lung cancer patient PBMC were greater than that observed from normal donors. A trend, although not significant, was observed in that higher levels of both Th1 and Th2 cytokines increased as the stage of the cancer increased. This was coupled with decreased thymidine incorporation of $\mathrm{T}$ cells in patients as their stage increased from I to III. In addition, flow cytometric analysis revealed higher levels of regulatory $\mathrm{T}$ cells (Tregs) in the leukapheresis products of NSCLC patients. Finally, tumor biopsies from NSCLC patients were compared to autologous normal adjacent tissue for their ability to secrete cytokines in response to both $\mathrm{T}$ cell and CD14 cell stimuli. The cytokine environment described in the current report is one characterized by high levels of cytokines with potential for inhibition due to the levels of IL-10 observed. This coupled with the high levels of Tregs suggests that immune response to lung cancer could be diminished. In addition, implications are discussed when considering the use of leukapheresis products as a source of anti-tumor effector cells to generate reagents for immunotherapy studies.

\section{Materials and methods}

Patients. Leukapheresis products were obtained from NSCLC patients. All stages (I-IV) and histological types (adenocarcinoma, squamous cell carcinoma, bronchio-alveolar cancer,
Table I. Dendritic cell vaccine patient characteristics.

\begin{tabular}{|c|c|c|c|}
\hline Patient $^{\mathrm{a}}$ & Histology ${ }^{\mathrm{b}}$ & Stage $^{c}$ & Treatment $^{\mathrm{d}}$ \\
\hline DC1 & $\mathrm{Sq}$ & IIIA & $\mathrm{Sg}, \mathrm{Ch}, \mathrm{XRT}$ \\
\hline DC2 & $\mathrm{Ad}$ & IIIA & $\mathrm{Ch}, \mathrm{XRT}$ \\
\hline DC3 & $\mathrm{Sq}$ & IIIA & $\mathrm{Sg}$ \\
\hline DC4 & $\mathrm{Ad}$ & IIB & $\mathrm{Sg}$ \\
\hline DC5 & $\mathrm{Sq}$ & IIIA & $\mathrm{Ch}, \mathrm{XRT}$ \\
\hline DC6 & $\mathrm{Ad}$ & IB & $\mathrm{Sg}$ \\
\hline DC7 & $\mathrm{Ad}$ & IIIA & $\mathrm{Sg}$ \\
\hline DC8 & BAC & Multifocal & $\mathrm{Sg}$ \\
\hline DC9 & Ad & IA & $\mathrm{Sg}$ \\
\hline DC10 & $\mathrm{Ad} / \mathrm{N}$ & IB & $\mathrm{Sg}, \mathrm{Ch}, \mathrm{SRT}$ \\
\hline DC11 & $\mathrm{Ad}$ & IB & $\mathrm{Sg}$ \\
\hline $\mathrm{DC} 12$ & $\mathrm{Ad}$ & IIIB & Ch, XRT \\
\hline DC13 & $\mathrm{Sq}$ & IIIA & SG, XRT \\
\hline DC14 & $\mathrm{Ad}$ & IIIB & Ch, XRT \\
\hline DC15 & $\mathrm{Ad}$ & IIIA & $\mathrm{Ch}, \mathrm{Sg}, \mathrm{XRT}$ \\
\hline DC16 & Ad & IIIA & $\mathrm{Sg}, \mathrm{Ch}, \mathrm{XRT}$ \\
\hline DC17 & $\mathrm{LC}$ & IB & $\mathrm{Sg}$ \\
\hline DC18 & $\mathrm{Ad}$ & IIIB & $\mathrm{Ch}, \mathrm{XRT}$ \\
\hline DC19 & $\mathrm{Sq}$ & IIIB & Ch, XRT \\
\hline DC20 & $\mathrm{Ad}$ & IA & $\mathrm{Sg}$ \\
\hline DC22 & $\mathrm{Sq}(\mathrm{BAC})$ & IIIA & Ch, XRT \\
\hline DC23 & $\mathrm{Ad} / \mathrm{Sq}$ & IB & $\mathrm{Sg}, \mathrm{Ch}, \mathrm{XRT}$ \\
\hline DC24 & LC & IIIA & Ch, XRT \\
\hline DC25 & $\mathrm{Sq}$ & IIIA & Ch, XRT \\
\hline DC26 & $\mathrm{Ad}$ & IA & $\mathrm{Sg}$ \\
\hline DC27 & BAC & IA & $\mathrm{Sg}$ \\
\hline DC28 & $\mathrm{LC}$ & IB & $\mathrm{Sg}, \mathrm{Ch}, \mathrm{XRT}$ \\
\hline DC29 & $\mathrm{Sq}$ & IIB & $\mathrm{Sg}, \mathrm{Ch}$ \\
\hline DC30 & $\mathrm{Ad}$ & IIIB & $\mathrm{Ch}, \mathrm{XRT}$ \\
\hline DC31 & Ad & IA & $\mathrm{Sg}$ \\
\hline DC32 & BAC & IB & $\mathrm{Sg}, \mathrm{Ch}$ \\
\hline DC33 & $\mathrm{Ad}$ & IIIA & $\mathrm{Sg}, \mathrm{Ch}, \mathrm{XRT}$ \\
\hline DC34 & $\mathrm{Sq}$ & IIIB & Ch, XRT \\
\hline DC35 & Ad & IIIA & $\mathrm{Sg}$ \\
\hline DC36 & BAC & Multifocal & $\mathrm{Ch}$ \\
\hline
\end{tabular}

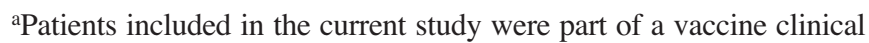
trial conducted by our group as previously described by Hirschowitz et al (23). 'Histology of the tumors included: Ad, adenocarcinoma; $\mathrm{Sq}$, squamous cell carcinoma; LC, large cell carcinioma, BAC, bronchio-alveolar cancer; $\mathrm{N}$, neuroendocrine; when 2 are listed it is a mixed disease. ${ }^{\mathrm{c}}$ Stage of cancer at entry into the protocol. ${ }^{\mathrm{d}}$ Prior therapy when patient entered the protocol. $\mathrm{Sg}$, surgery; $\mathrm{Ch}$, chemotherapy; XRT, radiation therapy.

large cell carcinoma and neuroendocrine) associated with the disease were represented in the study. Most patients had conventional therapies including surgery, chemotherapy, and/ or radiation therapy for their disease (Table I). The PBMC were obtained at least 6 weeks after the delivery of conventional therapies and at least 3 weeks prior to receiving immuno- 
therapy. The immunotherapy consisted of autologous DCs pulsed with apoptotic bodies derived from the allogeneic NSCLC cell line 1650 as previously described $(23,24)$.

Preparation of PBMC. Leukapheresis products were obtained from the University of Kentucky Hospital under local IRB approval and normal donor buffy coats were purchased from the Kentucky Blood Center. Both products were subjected to Ficoll Hypaque purification as previously described (7). In brief, cell products were diluted $1: 1$ in sterile PBS and layered onto Ficoll Hypaque in 50-ml sterile centrifuge tubes (13 ml Ficoll Hypaque; $30 \mathrm{ml}$ cell containing solution). Tubes were centrifuged at $400 \mathrm{x} \mathrm{g}$ for $30 \mathrm{~min}$. The buffy coats were removed and washed four times in medium containing FBS. Peripheral blood mononuclear cells were counted and assessed for cell viability using Trypan Blue analysis. PBMC were cryopreserved as previously described (25) for future immunological analysis.

Preparation of lung tumors and normal adjacent tissue. Fresh NSCLC tumor biopsies and normal adjacent lung tissue were obtained from the Cooperative human tissue network (CHTN). In a few cases, samples were obtained from the University of Kentucky Hospital under IRB approval. The tumor and NAT were given an identifier (UKY plus a number). The samples were minced to $3-\mathrm{mm}^{3}$ chunks and enzyme digested at $37^{\circ} \mathrm{C}$ (5\% $\mathrm{CO}_{2}$ in air environment) to single cell suspensions as previously described (26). The diced tissue samples were mixed with enzyme medium (40 $\mathrm{ml}$ of enzyme medium per gram of tissue) (27) and placed in sterile bottles containing a magnetic stir bar for 12-18 h. The enzyme medium was comprised of RPMI-1640 (Gibco-BRL) supplemented with DNAse $(30,000$ units/ml), collagenase $(1 \mathrm{~g} / \mathrm{l})$, hyaluronidase (100 mg/l), penicillin $(50 \mu \mathrm{g} / \mathrm{ml})$, streptomycin $(50 \mu \mathrm{g} / \mathrm{ml})$, amphotericin $(50 \mu \mathrm{g} / \mathrm{ml})$, and gentamycin sulfate $(10 \mu \mathrm{g} / \mathrm{ml})$. Following digestion, the samples were strained through a sterile $70-\mu \mathrm{m}$ mesh filter to remove clumps of fibrous material, centrifuged to collect cells and washed with PBS containing $5 \%$ fetal bovine serum (FBS) to neutralize residual enzymes in the medium. The cells were resuspended in X-VIVO 15 serum free medium, counted and assessed for cell viability using Trypan Blue exclusion technique. Single cell suspensions of solid tumor NAT which were $<60 \%$ viable were cleaned up using Ficoll Hypaque gradients as described above.

Cytokine release studies. Single cell suspensions of NSCLC tumor biopsy, NAT or PBMC obtained from NSCLC patients or normal donors were placed in cell culture at $1.0 \times 10^{6}$ cells per $\mathrm{ml}$ of culture medium, $1 \mathrm{ml} /$ well of 24 -well sterile cell culture plates. The medium was X-VIVO 15 serum free medium containing penn/strep and gentamycin. The cultures were either established alone or in the presence of plastic bound anti-CD3 (OKT3; $1 \mu \mathrm{g} / \mathrm{ml}$ of binding buffer) and $10 \mu \mathrm{g} / \mathrm{ml}$ soluble anti-CD28 mAb. PBMC from NSCLC patients and normal donors were also stimulated with the anti-TLR4 agonist LPS $(10 \mu \mathrm{g} / \mathrm{ml})$. The culture supernatants were removed after $24 \mathrm{~h}$, centrifuged at $400 \mathrm{x}$ g to remove residual cells, and cryopreserved until analyzed using commercial ELISA kits. The ELISA kits utilized were all obtained from BD PharMingen. The cytokines and their assay sensitivities were: $\gamma$ interferon, 4.7-300 pg/ml; IL-2, 7.8-500; TNF- $\alpha$, 7.8-500; GMCSF, 4.7-300 pg/ml; IL-6, 4.7-300 pg/ml; IL-10, 8-500 pg/ml; IL-13, 1.56-44.4 pg/ml; and IL-17, $0.75-100 \mathrm{pg} / \mathrm{ml}$.

Cell surface phenotyping: assessment of Tregs. Regulatory $\mathrm{T}$ cells (Tregs) were assessed by direct surface and intracellular staining with fluorescent antibodies detected using flow cytometry. Expression of Foxp3, a member of the forkhead/ winged-helix family of transcription factors, is considered a phenotypic marker for Tregs (28-31). PBMC, and cells extracted from tumor and normal adjacent lung tissue, were washed, counted, and resuspended at $1 \times 10^{6}$ per tube in $100 \mu 1$ staining buffer (PBS containing 1\% FBS and $0.1 \%$ sodium azide). Cells were surface stained with CD8 FITC, CD25 $\mathrm{PE}$ and CD4 PerCP (BD PharMingen) at $4^{\circ} \mathrm{C}$ in the dark for $30 \mathrm{~min}$, then washed three times with $2 \mathrm{ml}$ cold staining buffer. Intracellular staining was performed with APC antihuman Foxp3 staining set (eBioscience). Briefly, cells were resuspended in $1 \mathrm{ml}$ freshly diluted Fix/Perm solution, incubated at $4^{\circ} \mathrm{C}$ in the dark for $30 \mathrm{~min}$, washed three times with permeabilization buffer and stained at $4^{\circ} \mathrm{C}$ in the dark for an additional $30 \mathrm{~min}$. Tubes were washed twice, resuspended in $100 \mu 1$ staining buffer and analyzed on a BD FACScalibur with CellQuest software. Lymphocytes were gated by FSC/ SSC and data are presented as percent positive of this gate. In addition, standard 2-color analysis was done to assess leukocyte subsets in the PBMC samples using direct FITC and PE labeling. The antibodies included: anti-CD3 (T cells), anti-CD4 (helper T cells), anti-CD8 (cytolytic T cells) and anti-CD14 (monocytes).

Assessment of tritiated thymidine incorporation by PHA stimulated PBMC. The ability of PBMC from patients and normal donors to respond to the proliferative effects of PHA were measured by studying the incorporation of tritiated thymidine. In brief, PBMC from either normal donors or patients with NSCLC were plated at $1.0 \times 10^{5} /$ well of 96 -well microtiter plates in a volume of $200 \mu 1$ of X-VIVO 15 serum free medium. Conditions included PBMC alone or PBMC in the presence of 1 or $5 \mu \mathrm{g} / \mathrm{ml}$ of PHA. After 3 days, $1 \mu \mathrm{Ci}$ of tritiated thymidine was added and the plates harvested 16-18 h later using a Packard cell harvester, Meriden Cn.

In order to test the functional activity of cytokine containing supernatants, PHA responsiveness was tested in the presence or absence of supernatants obtained from both normal donors and patients with NSCLC. The cytokine supernatants obtained following 18-24-h incubation as described above were harvested, centrifuged at $400 \mathrm{x}$ g to remove residual cells and pooled and frozen until use. Normal donor sups were pooled from 10 normal donor experiments and the NSCLC sups were also pooled from 10 random donors with lung cancer. For PHA stimulation, PBMC obtained from 2 normal donors were tested at $1.0 \times 10^{5}$ cells per well in $200 \mu 1$ of medium in 96-well flat bottom microtiter plates. PHA was added at $1 \mu \mathrm{g}$ per well. After 4 days, $1 \mu \mathrm{Ci}$ of tritiated thymidine was added per well. After 18-24 h, the plates were harvested and bound tritiated thymidine counted using a Packard Top Count microplate scintillation counter 


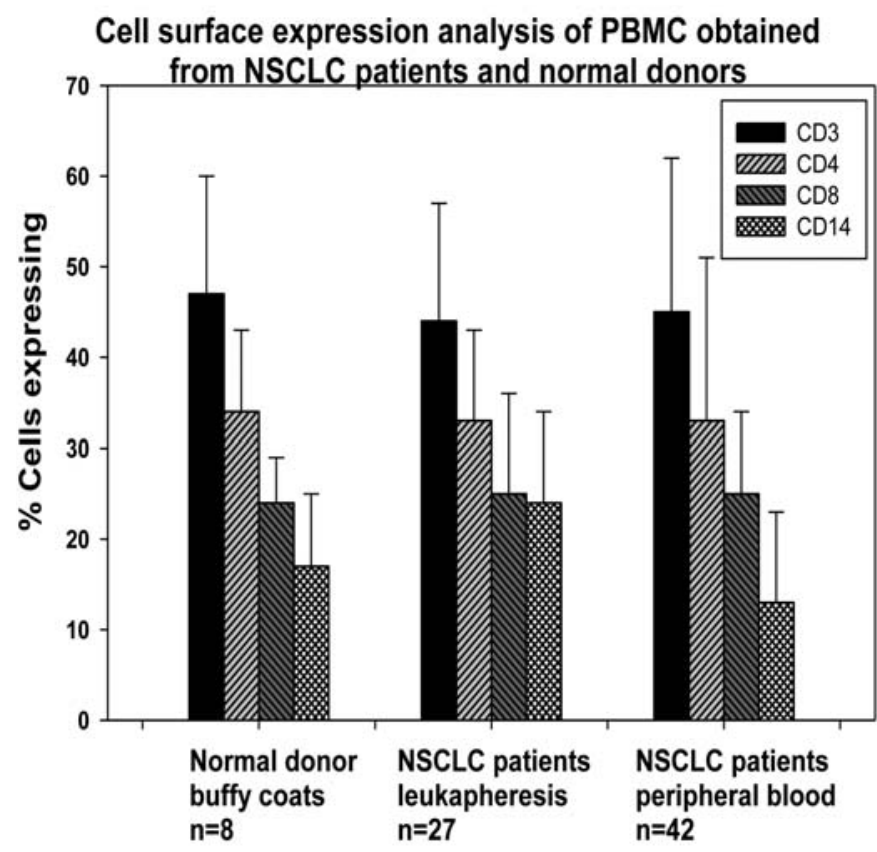

Figure 1. PBMC from normal donor buffy coats and NSCLC patients' peripheral blood and leukapheresis products were analyzed using direct cell surface phenotyping. The cells were stained with FITC or PE labeled antibodies to the T cell antigens CD3, CD4, CD8 and CD14 on monocytes. All samples were processed using Ficoll Hypaque separation medium. Note that the levels of each cell type were not significantly different from one another.

(Packard Instrument Company, Downers Grove, IL). The data were presented as either total $\mathrm{cpm}$ or stimulation index which was obtained by dividing the total experimental $\mathrm{cpm}$ by cpm for lymphocytes alone.

\section{Results}

Components of NSCLC patient leukapheresis products and normal donor buffy coats. Twenty-nine leukapheresis products and 42 peripheral blood bleeds obtained at post vaccine intervals were studied from patients enrolled in a dendritic cell vaccine trial being conducted by our group $(23,24)$. Ten buffy coats, prepared by the Kentucky Blood Center, were utilized as normal donor controls. Peripheral blood mononuclear cells (PBMC) obtained from the three sources following Ficoll Hypaque purification were dual stained for direct cell surface phenotyping. Observe similar populations of PBMC from patient leukapheresis, peripheral blood draws and normal donor buffy coat products (Fig. 1). $\mathrm{CD}^{+}$cells comprised $>40 \%$ of the whole cell population. $\mathrm{CD}^{+}$cells outnumbered $\mathrm{CD} 8^{+}$cells and $\mathrm{CD} 14^{+}$monocytes were slightly elevated in the leukapheresis products of NSCLC patients (24\% for patients; $18 \%$ for normal donors). There were no significant differences in the levels of any of the PBMC subtypes thus validating the comparisons of cytokine release presented below.

Patterns of cytokines secreted by PBMC from NSCLC patients and normal donors. PBMC from leukapheresis products and normal donor buffy coats were established in overnight culture either: i) alone; ii) in the presence of the
$\mathrm{T}$ cell receptor (TCR) stimulants plastic bound anti-CD3 monoclonal antibody (OKT3 mAb) and soluble CD28; or iii) the $\mathrm{CD} 14^{+}$cell stimulant TLR-4 agonist Lipopolysaccharide (LPS). Cytokines were measured after $24 \mathrm{~h}$ using standard ELISA. We examined levels of Th1 (IL-2, $\gamma$ interferon), Th2 (IL-10, IL-13), pro-inflammatory (TNF- $\alpha$, IL-6), Th17 (IL-17) and hematopoietic cytokine (GMCSF) from $\mathrm{T}$ cells and CD14+ monocytes.

Following TCR stimulation of PBMC, similar levels of $\gamma$-INF, TNF- $\alpha$, GMCSF and IL-17 were observed in both normal donors and patients with NSCLC. Significantly higher levels of the cytokines IL-2 ( $<<0.01)$, IL-10 ( $<<0.001)$, IL-13 ( $<<0.0001)$ and IL-6 $(\mathrm{p}<0.01)$ were observed from NSCLC patients compared to normal donor PBMC (Fig. 2). When the PBMC were stimulated with the TLR-4 agonist LPS, similar levels of IL-6 and GMCSF were observed. Interestingly, significantly higher levels of $\gamma$-INF $(\mathrm{p}<0.01)$, IL-10 $(\mathrm{p}<0.001)$ and TNF- $\alpha(\mathrm{p}<0.02)$ were found in the super-natants of NSCLC patient PBMC (Fig. 3). In the analysis of individual cytokines, significance was determined using Student's t-test.

Comparison of total Th1 and Th2 cytokines secreted by stage I-III NSCLC patients and normal donors. In Figs. 2 and 3, we compared levels of both Th1 and Th2 cytokines, individually, between 29 patients with NSCLC and 10 normal donors. While we observed differences between the 2 groups, we wanted to compare total levels of cytokines as a comparison. Protein cytokine levels $(\mathrm{pg} / \mathrm{ml}$ per million cells released in $24 \mathrm{~h}$ ) of Th1, Th2, GMCSF, and Pro-inflammatory cytokines were totaled, grouped and plotted for each donor group (normal donor and NSCLC patients) showing the heterogeneity in cytokine release. The levels of Th1 cytokines (IL-2 and $\gamma$ interferon, solid bars) (Fig. 4) increased from normal donors through stage I and III NSCLC patients (range of means: 407 to 803 to $958 \mathrm{pg} / \mathrm{million}$ PBMC). Interestingly, the increase in Th1 cytokines between normal donor and stage I patients was significant $(\mathrm{P}<0.038)$ as was the difference between normal donor and stage III patients $(\mathrm{P}<0.044)$. There was no significant difference in Th1 cytokines between stages I and III. More striking were the total levels of Th2 cytokines (IL-10 and IL-13) as they increased between normal donors (502 pg) to stage I patients $(1250 \mathrm{pg})$ to stage III patients (1591 pg). Again, statistically significant differences were noted between normal donor and stage I $(\mathrm{P}<0.041)$ and stage III $(\mathrm{P}<0.0048)$ NSCLC patients. Less striking was the increase in levels of the pro-inflammatory cytokines IL-6 and TNF- $\alpha$ (Fig. 4) with levels being higher but not statistically significant in stage III patients $(7685 \mathrm{pg}$ ) compared to stage I (7283 pg) and normal donors (6075 pg). The levels of GMCSF, however, remained similar between normal donors (1570 pg) and patients (stage I, $1611 \mathrm{pg}$; stage III 1816pg). The numbers of patients with stage II disease were not numerous enough $(n=2)$ to allow comparisons. In the analysis of total cytokines, significance was based on Wilcoxon rank sum statistics.

Tritiated thymidine incorporation by PBMC. PBMC from both normal donors and patients with NSCLC were then tested for their ability to incorporate tritiated thymidine 
Stimulation of PBMC with anti-CD3 /CD28
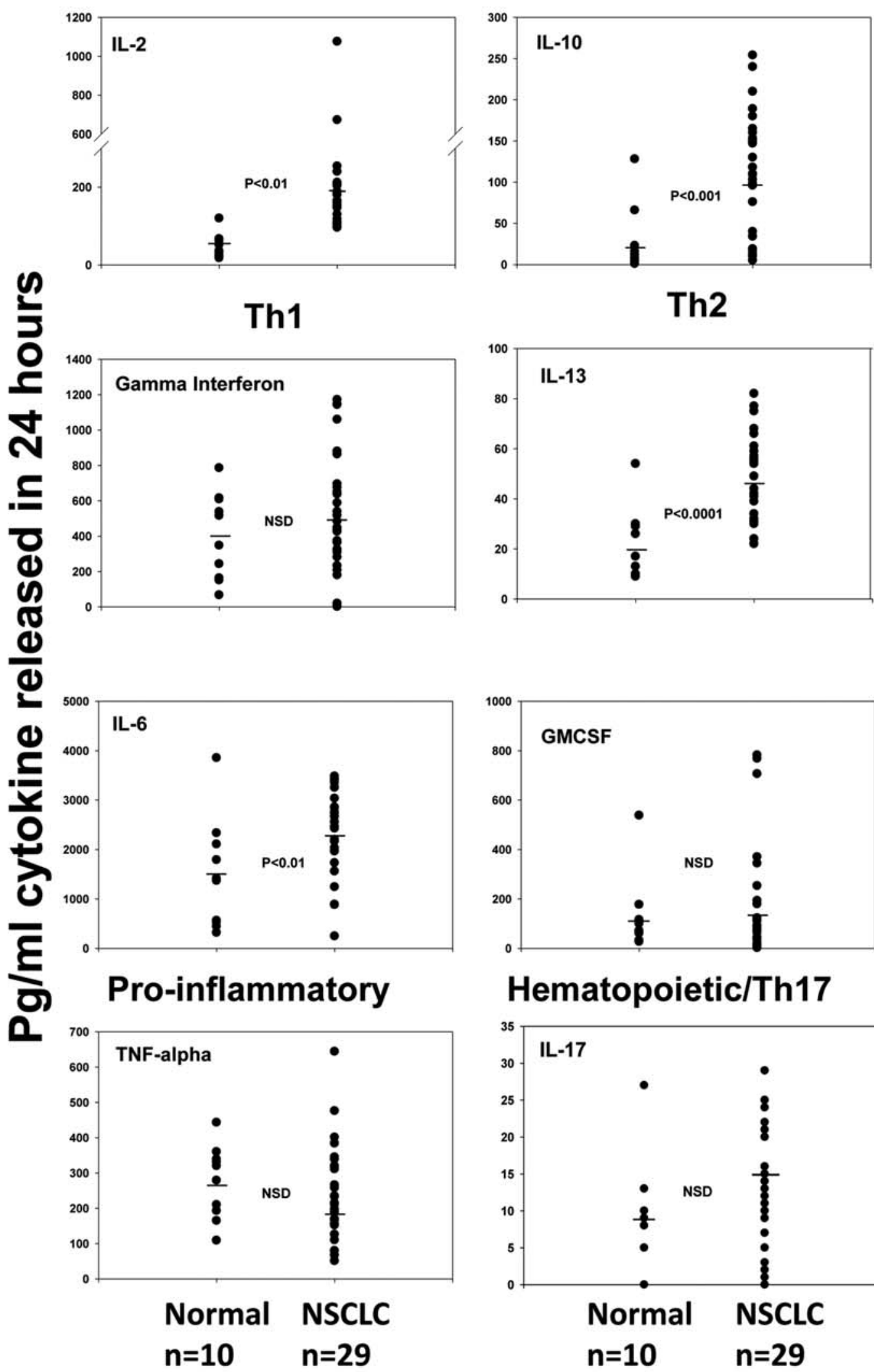

Th2
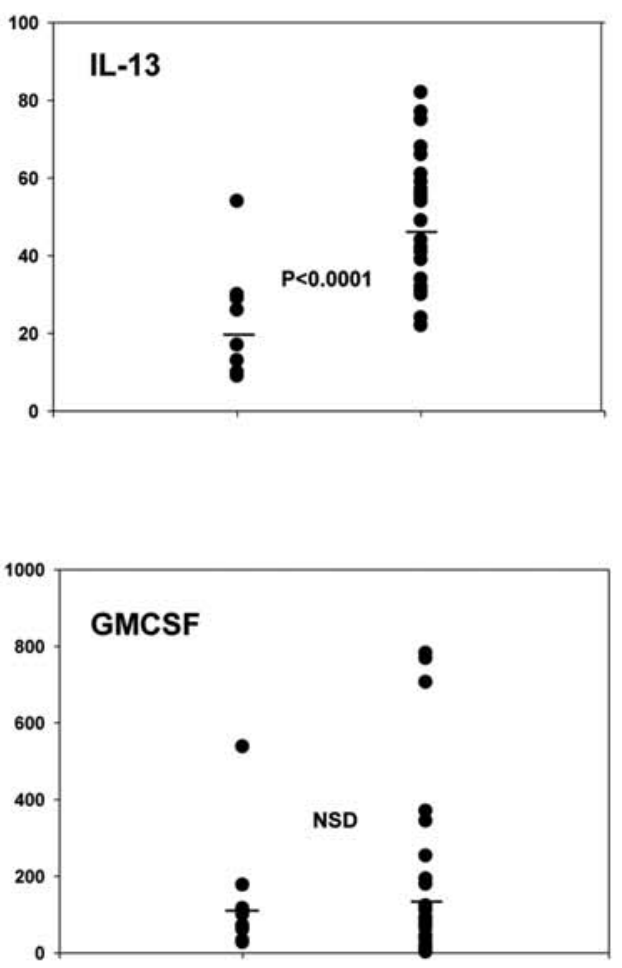

\section{Hematopoietic/Th17}

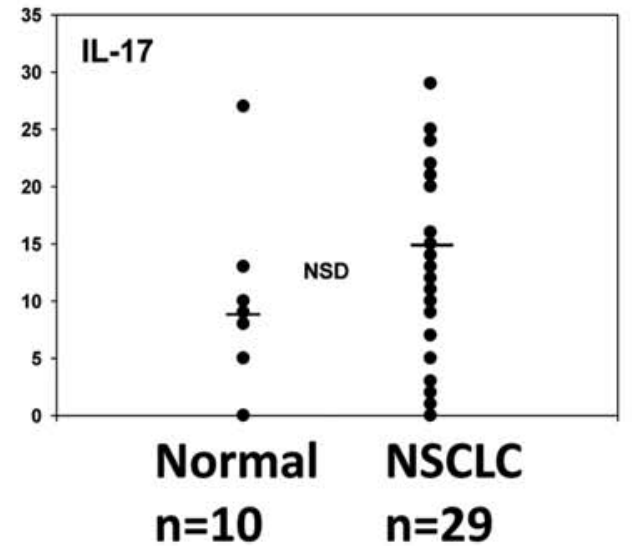

Figure 2. Cytokine release from T cells measured using ELISA as described in Materials and methods. Cytokines measured were: Th1, $\gamma$ interferon and IL-2; Th2, IL-10 and IL-13; Pro-inflammatory, IL-6 and TNF- $\alpha$; Hematopoietic, GMCSF; and Th17, IL-17. Samples of PBMC obtained from NSCLC patient leukapheresis products $(\mathrm{n}=29)$ were compared to PBMC obtained from normal donor buffy coats $(\mathrm{n}=10)$. As described, $1 \times 10^{6} \mathrm{PBMC}$ were cultured overnight either alone or in the presence of $1 \mu \mathrm{g}$ plastic bound anti-CD3 (OKT3) and soluble anti-CD28. Supernatants were removed and assayed for cytokine and results presented as $\mathrm{pg} / \mathrm{ml}$ cytokine released per million PBMC in $24 \mathrm{~h}$. Note that there was no significant difference (NSD) between the groups in the levels of: $\gamma$ interferon, TNF- $\alpha$, GMCSF, and IL-17. However, differences as determined using Student's t-test were significant for IL-2 (p<0.01), IL-6 (p<0.01), IL-10 (p<0.001) and IL-13 (p<0.0001). 


\section{Stimulation of PBMC with LPS}
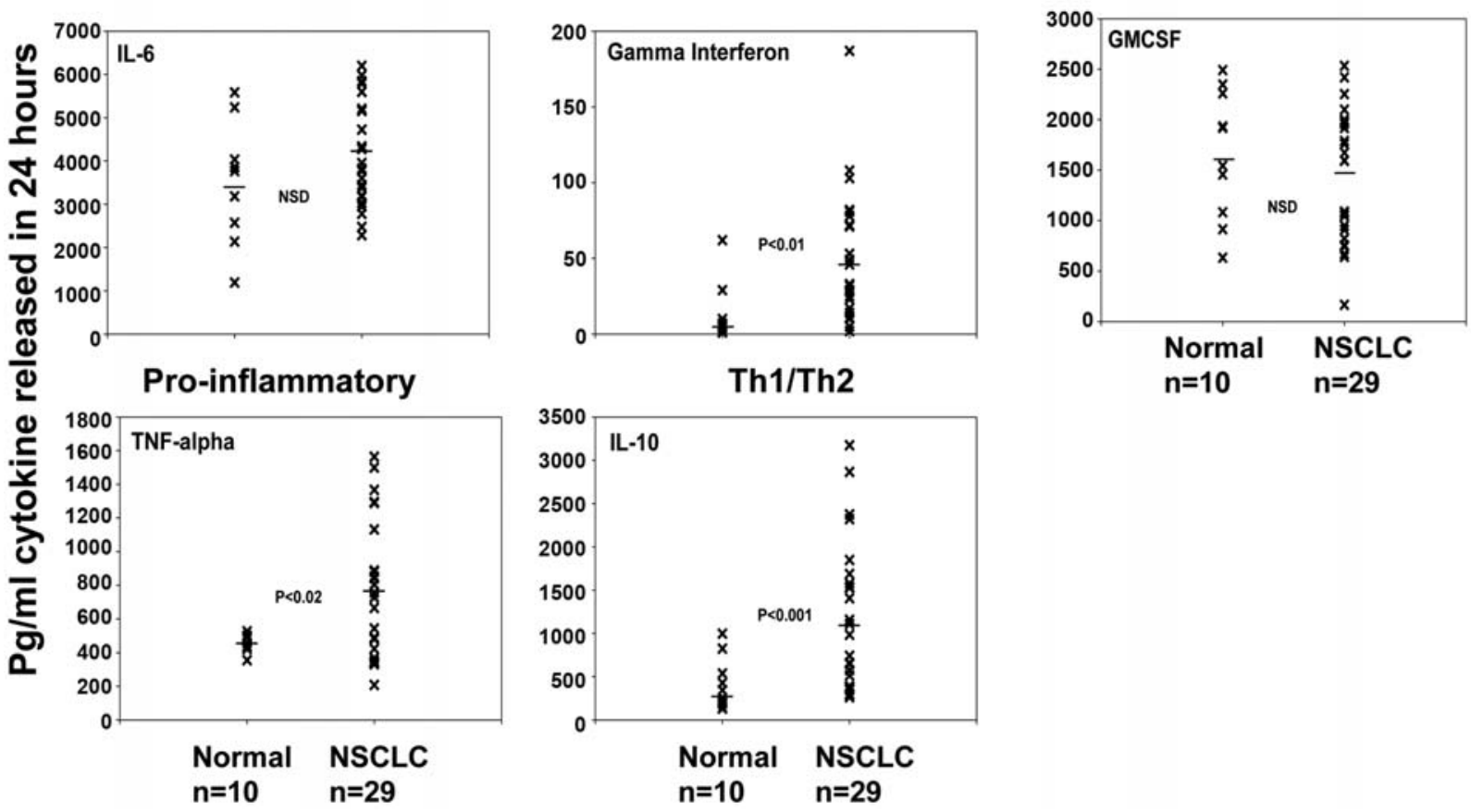

Figure 3. Cytokine release measured from monocytes using ELISA as described in Materials and methods. Cytokines measured were: Th1, $\gamma$ interferon; Th2, IL-10; Pro-inflammatory, IL-6 and TNF- $\alpha$; and Hematopoietic, GMCSF. Samples of PBMC obtained from NSCLC patient leukapheresis products $(n=29)$ were compared to PBMC obtained from normal donor buffy coats $(n=10)$. As described, $1 \times 10^{6}$ PBMC were cultured overnight either alone or in the presence of $10 \mu \mathrm{g} /$ well LPS. Supernatants were removed after $24 \mathrm{~h}$ and assayed for cytokine and results presented as pg/ml cytokine released per million PBMC in $24 \mathrm{~h}$. Note that there was no significant difference (NSD) between the groups in the levels of: IL-6 and GMCSF. However, differences were significant for TNF- $\alpha(\mathrm{p}<0.02) ; \gamma$ interferon $(\mathrm{p}<0.01)$; and IL-10 $(\mathrm{p}<0.001)$.

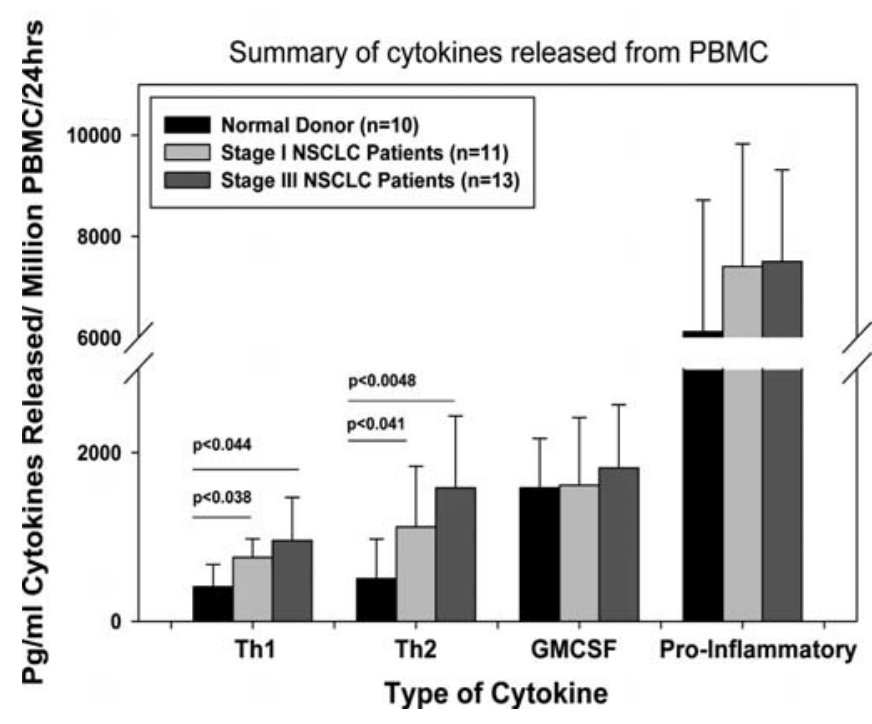

Figure 4. The amounts of secreted cytokines were compared between normal donors and patients with NSCLC. Total cytokine levels were obtained by adding the amounts of each type of cytokines released by both $\mathrm{T}$ cells and LPS stimulated monocytes in order to compare potential differences in cytokine microenvironments. The total cytokine levels were plotted comparing normal donors to stage I and III NSCLC patients enrolled in a clinical trial conducted by our group. Note that in general, levels of Th1 and Th2 cytokines were significantly higher in patients when compared to normal donors. While not significant, a trend also existed showing that levels of Th1 and Th2 cytokines increased as the stage of the patients increased. Levels of GMCSF did not appear to increase while levels of proinflammatory cytokines increased to a slight degree. Levels of significance were determined using Wilcoxon rank sum statistics. following exposure to either 1 or $5 \mu \mathrm{g} / \mathrm{ml}$ PHA. The PBMC were obtained from normal donor buffy coats or leukapheresis products of patients with NSCLC as described in Table I. Note in Fig. 5A that PBMC from normal donors incorporated more tritiated thymidine than both stage I and stage III NSCLC patients using either 1 or $5 \mu \mathrm{g} / \mathrm{ml}$ PHA. These data are presented as stimulation indices with a significant difference $(\mathrm{p}<0.05)$ observed in the SI between normal donor and stage III patients.

Effect of supernatants on normal donor PBMC response to $P H A$. Supernatants obtained from normal donor PBMC $(\mathrm{n}=10)$ and NSCLC patients $(n=29)$ stimulated with anti-CD3 and soluble anti-CD28 (Fig. 5A) were each pooled, filtered to remove cells and added at $25 \%$ volume/volume concentration to test the effect on PHA stimulated PBMC from 2 normal donors. In Fig. 5B, note that supernatants from NSCLC patients stimulated with anti-CD3 and CD28 were inhibitory $(\mathrm{p}<0.0001)$ to the PHA response of normal donor PBMC as measured by tritiated thymidine incorporation. Thus, cytokines contained in the supernatants appeared to be functionally active, in most cases, inhibitory to $\mathrm{T}$ cell functional response as measured by tritiated thymidine incorporation assay.

Patterns of cytokines secreted by NSCLC tumor biopsies compared to normal adjacent tissue (NAT). Nineteen paired samples of NSCLC tumor biopsies (generally 0.1-1.0 g of tissue obtained) and normal adjacent tissue (NAT) were obtained from the Cooperative Human Tissue Network 


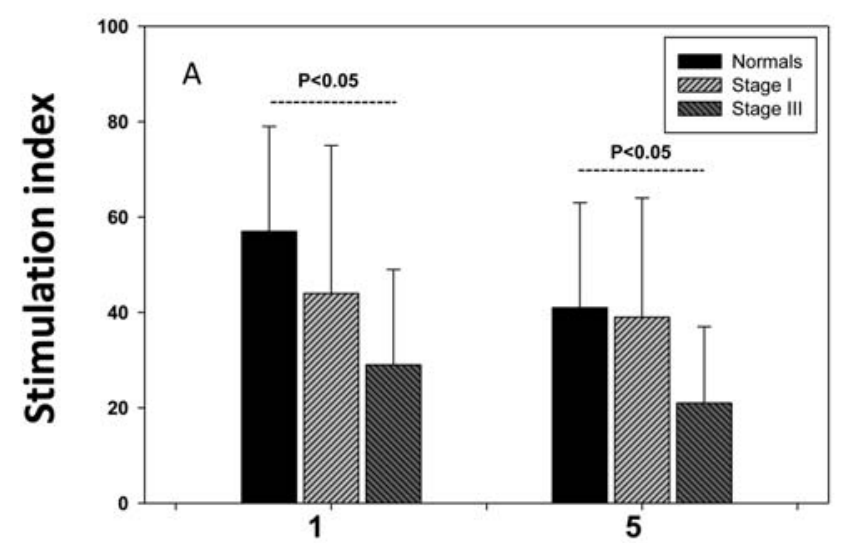

Concentration of PHA (micrograms $/ \mathrm{ml}$ )

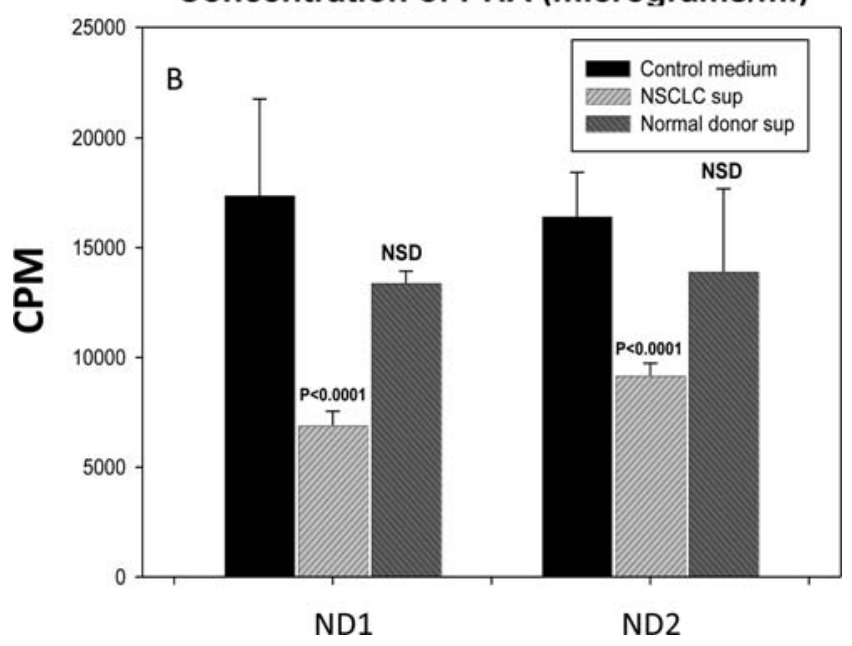

Figure 5. PBMC obtained from normal donors $(\mathrm{n}=10)$ and PBMC obtained from NSCLC patients $(n=29)$ were compared for their ability to respond to stimulation with either 1 or $5 \mu \mathrm{g} / \mathrm{ml}$ of the $\mathrm{T}$ cell mitogen PHA (A) The cultures were maintained for 3 days at which point $1 \mu \mathrm{Ci} / \mathrm{ml}$ tritiated thymidine was added per well and the culture continued overnight. Following 18-24 h, the wells were harvested and analyzed as described in Materials and methods. Note that higher levels of tritiated thymidine were obtained when cultures were stimulated with $1 \mu \mathrm{g}$ PHA compared to $5 \mu \mathrm{g}$. Note at both concentrations, that PBMC obtained from NSCLC patients incorporated more thymidine than PBMC obtained from patients with NSCLC Interestingly, PBMC from stage I patients had higher levels of thymidine incorporation compared to patients with stage III disease. While the levels were higher in normal donor PBMC, the only significant differences were noted when stage III NSCLC patients were compared to the thymidine incorporation by normal donor PBMC $(\mathrm{P}<0.05)$. Results are presented as stimulation index which was obtained by dividing the amount of cpm incorporated by experimental cultures ( 1 or $5 \mu \mathrm{g}$ PHA) by control cultures (no PHA condition). In (B), thymidine incorporation of normal donor PBMC and NSCLC patient PBMC were studied in the presence of supernatants containing cytokines obtained from patient and normal donor PBMC stimulated with OKT3 and anti-CD28. The volume of supernatant used was $25 \%$ of control medium. The assay was the same as described for the control experiments presented in (A). Note, that PBMC obtained from 2 separate normal donors incorporated thymidine similarly. However, when supernatant obtained from NSCLC patient PBMC were added to the normal donor cultures, the level of thymidine incorporation was significantly reduced $(\mathrm{P}<0.0001)$ for both donors. Supernatant from normal donor PBMC cultures, while reduced, were not significantly different than the control cultures.

(CHTN). The samples were enzyme digested overnight and treated similarly to PBMC as described above. Single cell suspensions of NAT and tumor were cultured either alone, with anti-CD3 monoclonal antibody (OKT3) or LPS for $24 \mathrm{~h}$.
The results of cytokine release assays for the Th1 cytokine $\gamma$ interferon and the Th2 cytokine IL-10 are presented in Table II. In general, cytokine release was variable with both $\gamma$ interferon and IL-10 detected in all samples studied. While nanogram levels of $\gamma$ interferon were observed from CD3 stimulated cells contained in tumor tissue, paired NAT samples also showed increased levels (see samples \# 123, $138,139,163,164$ and 186). While the mean for $\gamma$ interferon release was increased, the difference was not significant based on the range of levels detected. Similarly, IL-10 was secreted to some degree in both NAT and tumor tissue. A significant difference in IL-10 release was noted between LPS stimulated tumor and LPS stimulated NAT $(\mathrm{P}<0.001$; compare bold columns). Tumors and NAT cultures stimulated with anti-CD3 did not show appreciably higher levels of IL-10 when compared to cells incubated in the absence of stimulation.

\section{Levels of CD4 and CD8 regulatory $T$ cells (Tregs) in different} anatomic compartments of NSCLC patients: peripheral blood and tissue biopsies. Tregs were analyzed in patient leukapheresis products, normal donor buffy coats and tumors obtained from the CHTN. Paired normal adjacent lung samples were also analyzed. The cells were stained for surface expression of CD4 or CD8 and CD25. The double positive cells were then analyzed for expression of intracellular FoxP3. In Fig. 6A, observe that normal donors expressed low levels of both CD4 and CD8 cells co-expressing CD25 and intracellular FoxP3 $(<5 \%)$ when compared to NSCLC patient samples. Note that all leukapheresis products obtained from NSCLC patients contained high levels of Tregs ranging from 4 to $25 \%$. The levels of Tregs were significantly higher $(\mathrm{p}<0.05)$ in stage I patients compared to normal donors and also significantly higher $(\mathrm{p}<0.03)$ in stage III patients compared to normal donors. No differences, however, were noted between stage I and stage III patients. While CD4 levels were strikingly high, levels of CD8s expressing the regulatory phenotype were also elevated but not to the level of CD4 Tregs. When analyzing tumor vs. NAT, in 2 out of 3 cases levels of $\mathrm{CD} 4 \mathrm{CD} 25 \mathrm{FoxP} 3^{+}$cells were higher in tumor vs. NAT but in UKY113, higher levels of Tregs were observed in the NAT than the tumor biopsy.

\section{Discussion}

In the current study, immunologic analysis was performed on PBMC obtained from leukapheresis products of NSCLC patients. PBMC contained in normal donor buffy coats were used as comparative controls. We examined cytokine secretion from PBMC using ELISA, thymidine incorporation as an indicator of cell proliferation, and cell surface phenotyping to quantitate Tregs. In additional studies, we examined IL-10 and $\gamma$ interferon secretion from lung tumor biopsies and autologous normal adjacent lung. In the overall analyses of these data, NSCLC patients produced more cytokines, contained higher levels of Tregs in circulation and had a reduced lymphoid proliferative response than that observed in normal donors. The results in the current study are important and provide insight into the interactions that occur in vivo between growing cancers and both lymphoid and myeloid components 
Table II. Secretion of cytokines ${ }^{a}$ from single cell suspensions of normal adjacent tissue (NAT) and NSCLC tumor biopsies. ${ }^{b}$

\begin{tabular}{|c|c|c|c|c|c|c|c|c|c|c|c|c|}
\hline \multirow[b]{3}{*}{ Biopsy \# } & \multicolumn{6}{|c|}{$\gamma$ interferon } & \multicolumn{6}{|c|}{ IL-10 } \\
\hline & \multicolumn{3}{|c|}{ NAT } & \multicolumn{3}{|c|}{ Tumor } & \multicolumn{3}{|c|}{ NAT } & \multicolumn{3}{|c|}{ Tumor } \\
\hline & Alone $^{c}$ & OKT3 & LPS & Alone & OKT3 & LPS & Alone & OKT3 & LPS & Alone & OKT3 & LPS \\
\hline UKY-62 & 10 & 12 & 11 & 5 & 136 & 5 & 26 & 29 & 34 & 137 & 218 & 255 \\
\hline UKY-63 & 28 & 301 & 210 & 26 & 2480 & 62 & 201 & 178 & 224 & 171 & 401 & 565 \\
\hline UKY-64 & 80 & 1849 & 144 & 27 & 433 & 38 & 125 & 140 & 118 & 183 & 126 & 664 \\
\hline UKY-65 & 4 & 441 & 9 & 22 & 91 & 14 & 37 & 36 & 189 & 69 & 37 & 192 \\
\hline UKY-68 & 20 & 697 & 12 & 20 & 276 & 47 & 23 & 22 & 12 & 23 & 19 & 328 \\
\hline UKY-70 & 15 & 319 & 12 & 9 & 551 & 16 & 287 & 257 & 165 & 158 & 143 & 215 \\
\hline UKY-73 & 21 & 244 & 18 & 16 & 192 & 22 & 210 & 102 & 154 & 450 & 157 & 482 \\
\hline UKY-74 & 10 & 54 & 12 & 13 & 51 & 38 & 14 & 26 & 14 & 217 & 92 & 464 \\
\hline UKY-93 & 16 & 156 & 23 & 15 & 182 & 16 & 374 & 289 & 585 & 522 & 367 & 1575 \\
\hline UKY-99 & 6 & 110 & 14 & 5 & 175 & 6 & 4 & 16 & 81 & 24 & 38 & 266 \\
\hline UKY-115 & 17 & 76 & 20 & 23 & 163 & 29 & 34 & 36 & 35 & 57 & 47 & 187 \\
\hline UKY-123 & 50 & 1896 & 11 & 64 & 983 & 27 & 532 & 287 & 261 & 124 & 470 & 612 \\
\hline UKY-137 & 16 & 74 & 8 & 4 & 70 & 10 & 68 & 77 & 140 & 15 & 8 & 611 \\
\hline UKY-138 & 12 & 1132 & 16 & 24 & 894 & 84 & 94 & 41 & 206 & 114 & 227 & 336 \\
\hline UKY-139 & 162 & 7188 & 72 & 7 & 5075 & 7 & 35 & 16 & 162 & 177 & 191 & 300 \\
\hline UKY-141 & 20 & 764 & 32 & 10 & 81 & 16 & 28 & 29 & 15 & 15 & 9 & 545 \\
\hline UKY-163 & 106 & 1661 & 279 & 59 & 9393 & 228 & 157 & 235 & 370 & 133 & 247 & 331 \\
\hline UKY-164 & 30 & 3520 & 72 & 14 & 9839 & 212 & 159 & 155 & 215 & 93 & 104 & 370 \\
\hline UKY-186 & 58 & 2520 & 210 & 29 & 7107 & 56 & 127 & 122 & 157 & 62 & 77 & 181 \\
\hline Mean $^{\mathrm{d}}$ & 36 & 1211 & 62 & 21 & 2009 & 49 & 133 & 110 & 165 & 144 & 157 & 446 \\
\hline SD & 41 & 1750 & 84 & 16 & 1874 & 64 & 140 & 97 & 139 & 136 & 137 & $\begin{array}{c}316 \\
P<0.001\end{array}$ \\
\hline
\end{tabular}

${ }^{a}$ Cytokines IL-10 and $\gamma$ interferon were measured using ELISA as described in Materials and methods. ${ }^{b}$ Samples were obtained from CHTN. Both tumor samples and NAT were processed as described in Materials and methods. ${ }^{\circ}$ Conditions included: OKT3, anti-CD3 mAb; LPS or alone. Single cell suspensions were cultured $18-24 \mathrm{~h}$ in $1 \mathrm{ml}$ of culture medium. The cells were established at $1.0 \times 10^{6} / \mathrm{ml}$ and supernatants collected and cryopreserved as described. ${ }^{\mathrm{d}}$ Mean \pm the standard deviation. All groups were analyzed for statistical significance using Student's t-test. No differences were observed except for IL-10 secretion from NAT vs. tumor biopsy $(\mathrm{p}<0.001)$.

of the immune system. PBMC from lung cancer patients are clearly different than those obtained from normal donors, and likely reflect the influence of tumor in vivo. Since many investigators use leukapheresis products as a source of precursor cells for immunotherapy; consideration of these differences might lead to improved protocols for effector cell generation.

Previous in vitro studies examined cytokines secreted from stimulated and un-stimulated populations of PBMC obtained via venipuncture $(21,22)$. Venipuncture provides both plasma and cellular components obtained directly from venous circulation which is the easiest access for preparing clinical reagents and assessing immunotherapies. The current study extends these observations by examining PBMC obtained from lung cancer patient leukapheresis products. Leukapheresis is performed at the beginning of many immunotherapy protocols, provides larger numbers of PBMC and can be adjusted for preferentially collecting subsets of leuko- cytes (myeloid vs. lymphoid). The large scale processing of blood using closed collection procedures in leukapheresis machines provides adequate precursors for the generation of antigen pulsed DCs (32) and anti-tumor lymphocytes (33). Historically, leukapheresis was integral to lymphokine activated killer cell protocols (LAK) which provided the basis for many immunotherapies being tested today (34). Leukapheresis products, drawn from a central or peripheral line, undergo differential centrifugation returning plasma to the patient while enriching mononuclear cells. Despite differences in the manner used to obtain PBMC, we are confident in the similarity between the products based on the cell surface phenotyping results (Fig. 1). Overall, we believe the results presented provide important insight into the tumormicroenvironment conditioned by PBMC contained in leukapheresis products. PBMC derived cytokines likely influence both positively and negatively the differentiation of therapeutic effector cell precursors both in vivo or in vitro. 


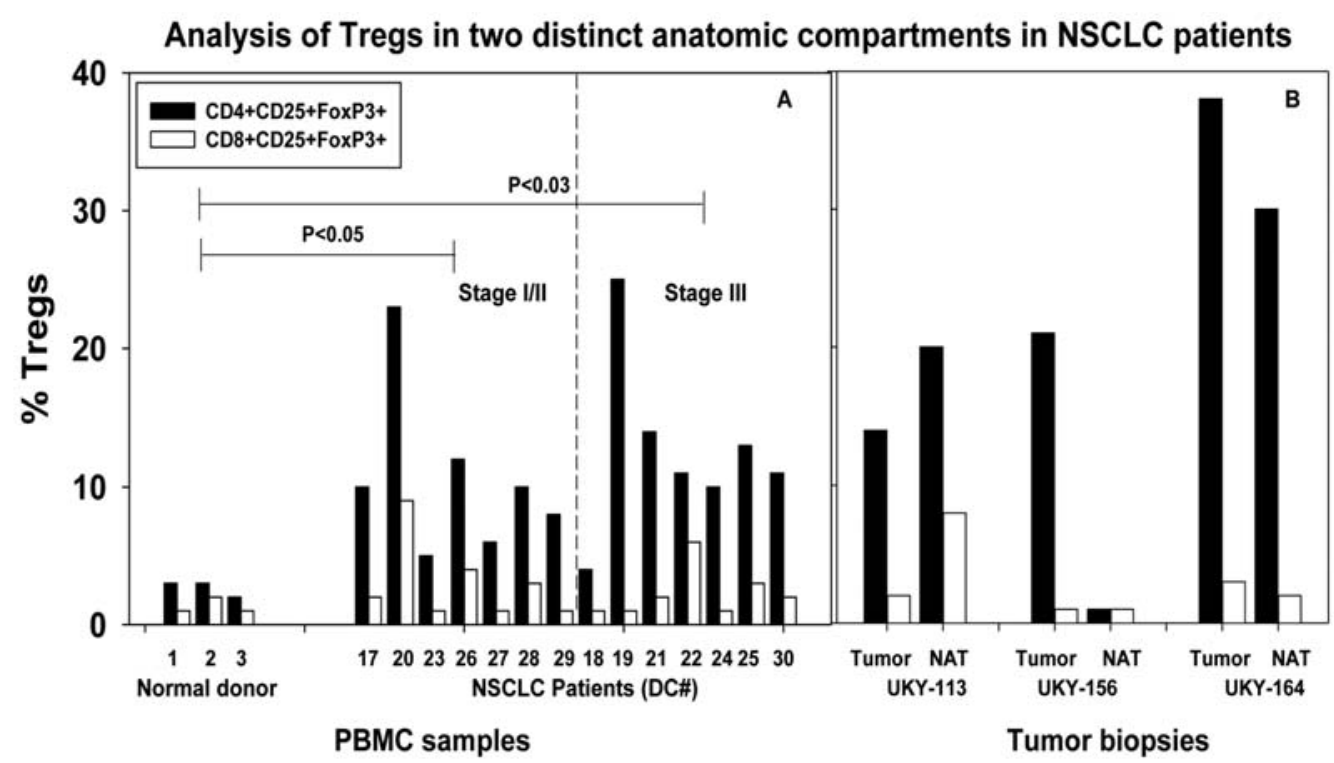

Figure 6. Levels of Tregs $\left(\mathrm{CD} 4^{+}\right.$or $\left.\mathrm{CD} 8^{+} / \mathrm{CD} 25^{+} / \mathrm{FoxP}^{+}\right)$were measured from normal donor buffy coats $(\mathrm{n}=3)$, NSCLC patient leukapheresis products $(n=14)$ and biopsies obtained from lung cancer patients $(n=3)$. Note that in general, the levels of Tregs from NSCLC patients were higher than those obtained from normal donors. In addition, in most cases, as expected, the levels of CD4 cells co-expressing CD25 and FoxP3 were higher than CD8 cells co expressing these markers. Also note in $2 / 3$ cases, the $\%$ of CD $4^{+}$Tregs was higher in lung cancer biopsies (UKY-156 and UKY-164) compared to autologous normal adjacent tissue. Observe in 113, however, a higher \% of Tregs was obtained from NAT compared to autologous tumor tissue.

The original classification of cytokines by Mosmann using murine $\mathrm{T}$ cell clones reflected cell of origin and the elicited cellular function (i.e., proliferation, differentiation, activation). This study attributed IL-2, $\gamma$ interferon and lymphotoxin secretion to T helper 1 cells (Th1) and IL-4, -5, -6, -10 and -13 secretion to Th2 cells (14). Similar patterns were reported for human $\mathrm{T}$ cell subsets (35). Certain cytokines including GMCSF, TNF- $\alpha$ and IL-3 were found to be released by both Th1 and Th2 cells. Reviewing the literature, however, reveals inconsistencies in the interpretation of these criteria with many investigators modifying the schema based on their own model systems. For instance, some studies list TNF- $\alpha$ as a Th1 cytokine and exclude IL- 6 as a Th 2 cytokine $(15,19,36)$. It is essential that standards be conformed to in order for studies to be comparable. In the present report, we developed a consensus based on the cancer literature. Thus we considered: IL-2 and $\gamma$ interferon as Th1; IL-10 and IL-13 as Th2; and TNF- $\alpha$ and IL-6 as pro-inflammatory cytokines. Using a similar schema, a study in prostate cancer showed both TNF- $\alpha$ and IL-6 were elevated along with PSA in hyperplasic prostate tissue (37). Finally, we included GMSCF as a hematopoietic cytokine and IL-17, a component of inflammation and autoimmunity, as a representative of the Th17 family.

Using ELISA, bulk levels of cytokines can be quantitated as they are released from PBMC in vivo or in vitro. In vivo release is measured in collected plasma, or plasma derived serum samples. In this fluid anatomic site, soluble cytokine levels are considered to reflect the in vivo steady state and ongoing immune reactions (38-40). These reactions are mediated by immune effector cells interacting with connective tissue cells, other supporting cells and in some cases tumor cells. When PBMC themselves are monitored by ELISA after 18-24-h culture, some protein may be carried over from the in vivo state. More importantly, Fan et al showed cytokines presented in the current study (i.e., $\gamma$ interferon, IL-2, IL-10, IL- 6 and TNF- $\alpha$ ), are produced between 1 and $8 \mathrm{~h}$ following receptor stimulation in vitro (PHA and anti-CD3) (41). Thus, the quality and quantity of cytokines measured is likely a reflection of pre-committed lymphoid and myeloid subsets mobilized to the periphery which have a phenotype determined by the health of the donor. TCR or TLR stimulation results in cytokine release from cells expanded in vivo providing insight into various disease states (42-46). These studies have shown predictable levels of both Th1 and Th2 cytokines in acute and chronically ill patients. The levels of cytokines observed differed from those obtained in age and sex matched normal donor controls.

In the current study, levels of some but not all Th1 and Th2 cytokines were significantly higher in NSCLC patients compared to normal donors. Only IL-10 was significantly different from TCR and TLR-4 stimulated PBMC. When the total levels of cytokines were presented, it was clear that both Th1 and Th2 cytokines were elevated in NSCLC patients over normal donors. A trend was also observed for an increase in both Th1 and Th2 cytokines between stage I and III patients, although the difference was not significant based on the sample size. In some previous studies of cancer, the levels of Th1 cytokines were reported to be similar between normal donors and cancer patients (melanoma, basal cell carcinoma, colorectal and prostate cancer) while significant differences were noted in the level of Th2 cytokines (47-50). The present study extends this observation measuring PBMC derived cytokines from leukapheresis products. It is important to note that the cytokines considered to be Th1 and Th2 between the present study and others is sometimes different, thus it is difficult to make direct comparisons. In NSCLC, prior studies showed increased Th2 cytokine levels such as 
IL-4, IL-6 and -10 comparing levels of mRNA (21) as well as RT-PCR analysis (20). This was partially confirmed in the present study since we measured both IL-10 and IL-13, not IL-4 and considered IL-6 a representative of Proinflammatory cytokines. Regardless, the combined results describe a micro-environment of cytokines in cancer patients which is elevated compared to normal donors. The potential effect on anti-tumor responses is likely influenced in either a positive or negative way. The effect in tumor lesions is probably dependent upon particular cytokines present at the interface of tumor and lymphoid and/or myeloid cells.

Pro-inflammatory cytokines TNF- $\alpha$ and IL-6, also studied in the present report, were shown to be associated with the pathogenesis of cancer and the related cachexia (51). In NSCLC, Fortunati et al reported an increase in the serum levels of both TNF- $\alpha$ and IL-6 in lung cancer patients. While TNF- $\alpha$ secretion was associated with PBMC, the same was not true for IL-6. The source of IL-6 was suggested to be the tumor mass. The current study supports the TNF- $\alpha$ finding but also showed that IL- 6 cytokine was actively transcribed in receptor stimulated T cells; with nanogram quantities per million cells detected by ELISA studies.

In an antigen independent system, we compared $\mathrm{T}$ cells from normal donors to those obtained from NSCLC patients for their ability to incorporate tritiated thymidine into DNA in response to PHA. While thymidine incorporation in the strictest sense is not a direct measure of $\mathrm{T}$ cell proliferation and expansion, increased thymidine incorporation was accompanied by an increase in the number of blastic lymphoid colonies observed in the microtiter wells (data not shown). The highest level of thymidine incorporation was noted in the PBMC obtained from normal donors. Levels of incorporation decreased in stage I NSCLC patients and was significantly reduced in stage III patients. This finding suggested that NSCLC patients have a decreased proliferative response that changes to a less favorable state as the stage of the patient increases. Earlier studies in head and neck cancer showed a similar decreased proliferative response (52). In lung cancer, the response to PHA was also reduced as the stage of disease increased from I to III (53). Monocyte depletion partially restored the thymidine incorporation, suggesting monocyte derived cytokines were contributing to the decreased $\mathrm{T}$ cell response. In the current study, supernatants from stimulated $\mathrm{T}$ cell cultures were inhibitory to the thymidine incorporation observed. We speculate that higher levels of Th2 cytokines could contribute to reduced thymidine incorporation observed. While not tested directly, this is corroborated by prior studies $(54,55)$. Unfortunately, in a prospective follow-up study, thymidine incorporation could not provide an accurate assessment of the overall status of cellular immunity in cancer (56), even though $\mathrm{T}$ cell response to $\mathrm{T}$ cell mitogens and TCR stimulation is often used as a measure of immune competence in young vs. aged individuals (57). Perhaps, decreased thymidine incorporation, taken together with higher levels of Th2 cytokines observed in cancer patients, could together predict immune responsiveness. Such a study should be done prospectively in order to validate the approach.

The progression of cancer from a non-vascularized aggregate of transformed cells into a mature vascularized tumor lesion occurs in the presence of both innate and acquired immune components. In spite of this, the tumor evolves as a result of evading recognition through both tumor-derived and host-derived soluble mediators (cytokines) and cells. The immunosuppressive cells are comprised predominantly of two types, myeloid-derived suppressor cells (MDSCs) (13) and Tregs $(11,12)$. While MDSCs were not evaluated in the current report, evidence exists that they are potent inhibitors of immunity to lung cancer. Tregs, which comprise 5-10\% of all $\mathrm{CD}^{+}$cells in normal donors (58) can range between $20-25 \%$ in cancer patient peripheral circulation (12). Tregs have also been identified in tumor tissue, pleural effusions, and in draining lymph nodes $(11,58-60)$. Interestingly, $\mathrm{CD}^{+}{ }^{+} \mathrm{CD} 25^{+} \mathrm{FOXP}^{+}$cells were found to be selectively drawn to tumor sites (tumor Tregs) by the expression of CCL22 by tumor macrophages and tumor cells (61). This accumulation was correlated with poor clinical outcome. In the present study, Tregs were found to be more numerous in the leukapheresis products of NSCLC patients compared to normal donors. It is fair to speculate the levels of Th2 cytokines and the reduced proliferative potential of lymphocytes is caused in part by the influences exerted by the higher levels of Tregs. Their presence in lung tumors have been shown to decrease lymphocyte proliferative potential (12). In addition, while statistically significant differences in Tregs were noted between normal donors and NSCLC patients, their increased levels were not observed between stages I and III as was shown for the reduction in proliferative potential. This suggests that a threshold level of Tregs are generated in early stages of cancer and appear to be functionally maintained throughout the disease state.

The peripheral blood contains leukocytes newly emigrated from the bone marrow as well as cells committed to antigen in peripheral tissues. These circulating PBMC provide protection against systemic disease. Tumor sites contain variable levels of leukocytes which have been implicated in disease prognosis; that is, more leukocytes, better predicted outcomes $(62,63)$. In NSCLC, their presence was correlated with improved survival (64). Intratumoral leukocytes may be found directly adjacent to tumor cells as well as in peritumoral regions in the parenchyma and around tumor vasculature. Tumor associated leukocytes include variable numbers of tumor associated macrophages (Tam), DCs, granulocytes as well as lymphocytes termed tumor infiltrating lymphocytes (TIL). In a number of different tumor histologies, TIL have been shown to have anti-tumor reactivity (65). Interestingly, using RT-PCR it was shown that high levels of the immunosuppressive cytokines IL-10 and TGF- $\beta$ could be localized to tumor infiltrating cells (66). These high levels of Th2 cytokines were also found in patient sera which was inhibitory to $\mathrm{T}$ cell proliferation. In NSCLC, using in situ hybridization, it was shown that both pleural fluid and tumor samples contained large numbers of IL-4, IL-10, and TGF- 3 secreting cells with remarkably lower number of cells secreting the Th1 cytokines IL-2, IL-12, IL-18 and $\gamma$ interferon (67-69).

In the current study, we measured both $\gamma$ interferon and IL-10 from 19 NSCLC tumor samples and paired autologous normal adjacent tissue. We examined cytokine release over $24 \mathrm{~h}$ in the absence and presence of either CD3 or TLR-4 stimulation and detected heterogeneous quantities of cytokine in each sample examined. This heterogeneity in 
$\gamma$ interferon and IL-10 noted in both NAT and tumor probably reflected the variability in leukocyte numbers and subsets in each site at the time of biopsy (data not shown). In samples stimulated with anti-CD3, there appeared to be more $\gamma$ interferon in tumor samples when compared to normal adjacent tissue (NAT) but it did not reach a level of significance. In contrast, tumor biopsies stimulated with LPS released consistently higher levels of IL-10 than autologous NAT samples $(\mathrm{p}<0.001)$. But, variable levels of IL-10 were noted in the NAT. A contributing factor could be PBMC emigrating from the blood since we have shown that blood derived PBMC were a potent source of IL-10. It was also not clear that NAT samples received by the lab were tumor free. Either case, the overall microenvironment of tumor derived from lung was observed to be a Th2 in nature. With that said, the different levels of $\gamma$ interferon observed affirm that Th1/Th2 balance is not rigid but variable from lesion to lesion. Considering the metastatic nature of many solid cancers; Th2 cytokines are likely associated with more progressive disease within the synapse between immune cells and tumor. In these cases, tumor progression may be favored rather than the development of the more desirable anti-tumor immunity.

An experimental anti-tumor therapy, immunotherapy, pioneered in the early 1980s using IL-2 and lymphokine activated killer cells (LAK), has evolved to include tumor antigen-specific effector mechanisms. Immunotherapy has been delivered alone or together with conventional therapies. Vaccines are currently the focus of immunotherapy utilizing tumor associated antigens delivered with autologous dendritic cells as antigen presenting cells. Vaccines are commonly used to increase the precursor frequency of specific anti-tumor effector cells and/or plasma cells secreting antibodies. There have been some cases of tumor regression $(23,24,67,70,71)$. Considering that the source of DCs is usually leukapheresis products, it is plausible that limited successes are due in part to the nature of cancer patient derived PBMC as described in the current report. Perhaps reducing the immunosuppressive nature of these PBMC could amplify potential anti-tumor responses. Murine studies have shown that the depletion of Tregs in vivo resulted in maximal tumor rejection (72) and, depletion of human Tregs enhanced CD8 T cell responses following DNA immunization (73). Recent reports from the NCI combined cellular therapy with attempts to reduce the levels of regulatory $\mathrm{T}$ cells in melanoma (74). Improved response rates were reported. Remaining cognizant of the suppressive nature of PBMC obtained in leukapheresis products (levels of IL-10 and Tregs, reduced proliferative potential) and designing in vitro and in vivo means to neutralize this suppression, could be beneficial to researchers and allow the development of more potent immunotherapeutic approaches.

\section{Acknowledgements}

We acknowledge the numerous patients who under IRB consent provided the large number of reagents for the studies described. In addition, we dedicate this study to Dr Bonnie Sigafus who passed away in June of 2008. Bonnie tirelessly provided the opportunity for funds for studies in lung cancer in the state of Kentucky. Bonnie will be missed by both the Universities of Louisville and Kentucky for her contribution to lung cancer research. This work was supported by funds obtained from: NIH-RO-1 number CA076300, the Cancer Research Institute (CRI) and the Kentucky Lung Cancer Research Fund (KLCR).

\section{References}

1. Greenlee RT, Murray T, Bolden S and Wingo PA: Cancer statistics, 2000. CA Cancer J Clin 50: 7-33, 2000.

2. Jemal A, Murray T, Samuels A, Ghafoor A, Ward E and Thun MJ: Cancer statistics, 2003. CA Cancer J Clin 53: 5-26, 2003.

3. Schiller JH: Lung cancer: therapeutic modalities and cytoprotection. Lung 176: 145-164, 1998.

4. Haura EB: Treatment of advanced non-small-cell lung cancer: a review of current randomized clinical trials and an examination of emerging therapies. Cancer Control 8: 326-336, 2001.

5. Breathnach OS, Freidlin B, Conley B, et al: Twenty-two years of phase III trials for patients with advanced non-small-cell lung cancer: sobering results. J Clin Oncol 19: 1734-1742, 2001

6. Ortegel JW, Staren ED, Faber LP, Warren WH and Braun DP: Modulation of tumor-infiltrating lymphocyte cytolytic activity against human non-small cell lung cancer. Lung Cancer 36: 17-25, 2002.

7. Yannelli JR, Hirscowitz E and Wroblewski JM: Growth and functional reactivity of lymphocytes obtained from three anatomic compartments in patients with non-small-cell lung cancer (NSCLC). Cancer Biother Radiopharm 18: 735-749, 2003.

8. Passlick B, Sienel W, Seen-Hibler R, Wockel W, Thetter O and Pantel K: The 17-1A antigen is expressed on primary, metastatic and disseminated non-small cell lung carcinoma cells. Int J Cancer 87: 548-552, 2000.

9. Watanabe Y, LePage S, Elliott M, et al: Characterization of preexisting humoral immunity specific for two cancer-testis antigens overexpressed at the mRNA level in non-small cell lung cancer. Cancer Immun 6: 3, 2006.

10. Ishibashi Y, Tanaka S, Tajima K, Yoshida T and Kuwano H: Expression of Foxp3 in non-small cell lung cancer patients is significantly higher in tumor tissues than in normal tissues, especially in tumors smaller than $30 \mathrm{~mm}$. Oncol Rep 15: 1315-1319, 2006.

11. Woo EY, Chu CS, Goletz TJ, et al: Regulatory CD4(+)CD25(+) $\mathrm{T}$ cells in tumors from patients with early-stage non-small cell lung cancer and late-stage ovarian cancer. Cancer Res 61: 4766-4772, 2001.

12. Woo EY, Yeh H, Chu CS, et al: Cutting edge: regulatory $\mathrm{T}$ cells from lung cancer patients directly inhibit autologous $\mathrm{T}$ cell proliferation. J Immunol 168: 4272-4276, 2002.

13. Srivastava MK, Bosch JJ, Thompson JA, Ksander BR, Edelman MJ and Ostrand-Rosenberg S: Lung cancer patients' CD4(+) T cells are activated in vitro by MHC II cell-based vaccines despite the presence of myeloid-derived suppressor cells. Cancer Immunol Immunother 57: 1493-1504, 2008.

14. Mosmann TR and Sad S: The expanding universe of T-cell subsets: Th1, Th2 and more. Immunol Today 17: 138-146, 1996.

15. Romagnani S: Regulation of the T cell response. Clin Exp Allergy 36: 1357-1366, 2006.

16. Bettelli E, Korn T and Kuchroo VK: Th17: the third member of the effector T cell trilogy. Curr Opin Immunol 19: 652-657, 2007.

17. Kaiko GE, Horvat JC, Beagley KW and Hansbro PM: Immunological decision-making: how does the immune system decide to mount a helper T-cell response? Immunology 123: 326-338, 2008.

18. Powrie F and Coffman RL: Inhibition of cell-mediated immunity by IL4 and IL10. Res Immunol 144: 639-643, 1993.

19. Romagnani S: The Th1/Th2 paradigm. Immunol Today 18: 263-266, 1997.

20. Wei H, Sun R, Xiao W, et al: Type two cytokines predominance of human lung cancer and its reverse by traditional Chinese medicine TTMP. Cell Mol Immunol 1: 63-70, 2004.

21. Asselin-Paturel C, Echchakir H, Carayol G, et al: Quantitative analysis of Th1, Th2 and TGF-betal cytokine expression in tumor, TIL and PBL of non-small cell lung cancer patients. Int J Cancer 77: 7-12, 1998.

22. Ito N, Suzuki Y, Taniguchi Y, Ishiguro K, Nakamura H and Ohgi S: Prognostic significance of T helper 1 and 2 and T cytotoxic 1 and 2 cells in patients with non-small cell lung cancer. Anticancer Res 25: 2027-2031, 2005. 
23. Hirschowitz EA, Foody T, Hidalgo GE and Yannelli JR: Immunization of NSCLC patients with antigen-pulsed immature autologous dendritic cells. Lung Cancer 57: 365-372, 2007.

24. Hirschowitz EA, Foody T, Kryscio R, Dickson L, Sturgill J and Yannelli J: Autologous dendritic cell vaccines for non-smallcell lung cancer. J Clin Oncol 22: 2808-2815, 2004.

25. Best A, Hidalgo G, Mitchell $\mathrm{K}$ and Yannelli JR: Issues concerning the large scale cryopreservation of peripheral blood mononuclear cells (PBMC) for immunotherapy trials. Cryobiology 54: 294-297, 2007.

26. Yannelli JR, McConnell S, Parker L, et al: Melanoma tumorinfiltrating lymphocytes derived from four distinct anatomic sites obtained from a single patient: comparison of functional reactivity and melanoma antigen recognition. J Immunother Emphasis Tumor Immunol 18: 263-271, 1995 .

27. Yannelli JR, Hyatt C, Johnson S, Hwu P and Rosenberg SA: Characterization of human tumor cell lines transduced with the cDNA encoding either tumor necrosis factor alpha (TNF-a) or interleukin-2 (IL-2). J Immunol Methods 161: 77-90, 1993.

28. Fontenot JD, Gavin MA and Rudensky AY: Foxp3 programs the development and function of $\mathrm{CD} 4{ }^{+} \mathrm{CD} 25^{+}$regulatory $\mathrm{T}$ cells. Nat Immunol 4: 330-336, 2003

29. Fu S, Zhang N, Yopp AC, et al: TGF-beta induces Foxp3 + Tregulatory cells from $\mathrm{CD} 4^{+} \mathrm{CD} 25^{-}$precursors. Am J Transplant 4: 1614-1627, 2004

30. Hori S, Nomura T and Sakaguchi S: Control of regulatory T cell development by the transcription factor Foxp3. Science 299: 1057-1061, 2003

31. Hori S and Sakaguchi S: Foxp3: a critical regulator of the development and function of regulatory T cells. Microbes Infect 6: 745-751, 2004.

32. Yannelli JR, Sturgill J, Foody T and Hirschowitz E: The large scale generation of dendritic cells for the immunization of patients with non-small cell lung cancer (NSCLC). Lung Cancer 47: 337-350, 2005.

33. Graff-Dubois S, Faure O, Gross DA, et al: Generation of CTL recognizing an HLA-A*0201-restricted epitope shared by MAGE-A1,-A2, -A3, -A4, -A6, -A10, and -A12 tumor antigens: implication in a broad-spectrum tumor immunotherapy. J Immunol 169: 575-580, 2002

34. Rosenberg SA, Lotze MT, Muul LM, et al: Observations on the systemic administration of autologous lymphokine-activated killer cells and recombinant interleukin-2 to patients with metastatic cancer. N Engl J Med 313: 1485-1492, 1985.

35. Del Prete GF, De Carli M, Mastromauro C, et al: Purified protein derivative of Mycobacterium tuberculosis and excretory-secretory antigen(s) of Toxocara canis expand in vitro human T cells with stable and opposite (type $1 \mathrm{~T}$ helper or type $2 \mathrm{~T}$ helper) profile of cytokine production. J Clin Invest 88: 346-350, 1991

36. Romagnani S: T-cell subsets (Th1 versus Th2). Ann Allergy Asthma Immunol 85: 9-21, 2000.

37. Bouraoui Y, Ricote M, Garcia-Tunon I, et al: Pro-inflammatory cytokines and prostate-specific antigen in hyperplasia and human prostate cancer. Cancer Detect Prev 32: 23-32, 2008.

38. Nemunaitis J, Fong T, Shabe P, Martineau D and Ando D: Comparison of serum interleukin-10 (IL-10) levels between normal volunteers and patients with advanced melanoma. Cancer Invest 19: 239-247, 2001

39. De Vita F, Orditura M, Galizia G, et al: Serum interleukin-10 levels as a prognostic factor in advanced non-small cell lung cancer patients. Chest 117: 365-373, 2000.

40. Neuner A, Schindel M, Wildenberg U, Muley T, Lahm H and Fischer JR: Prognostic significance of cytokine modulation in non-small cell lung cancer. Int J Cancer 101: 287-292, 2002.

41. Fan J, Nishanian P, Breen EC, McDonald M and Fahey JL: Cytokine gene expression in normal human lymphocytes in response to stimulation. Clin Diagn Lab Immunol 5: 335-340, 1998.

42. Capo C, Zaffran Y, Zugun F, Houpikian P, Raoult D and Mege JL: Production of interleukin-10 and transforming growth factor beta by peripheral blood mononuclear cells in Q fever endocarditis. Infect Immun 64: 4143-4147, 1996.

43. Esnault S, Benbernou N, Lavaud F, Shin HC, Potron G and Guenounou M: Differential spontaneous expression of mRNA for IL-4, IL-10, IL-13, IL-2 and interferon-gamma (IFNgamma) in peripheral blood mononuclear cells (PBMC) from atopic patients. Clin Exp Immunol 103: 111-118, 1996.

44. Gomes JA, Bahia-Oliveira LM, Rocha MO, Martins-Filho OA, Gazzinelli G and Correa-Oliveira R: Evidence that development of severe cardiomyopathy in human Chagas' disease is due to a Th1-specific immune response. Infect Immun 71: 1185-1193, 2003.
45. Fan J, Bass HZ and Fahey JL: Elevated IFN-gamma and decreased IL-2 gene expression are associated with HIV infection. J Immunol 151: 5031-5040, 1993

46. Schulze-Koops H, Lipsky PE, Kavanaugh AF and Davis LS: Elevated Th1- or Th0-like cytokine mRNA in peripheral circulation of patients with rheumatoid arthritis. Modulation by treatment with anti-ICAM-1 correlates with clinical benefit. J Immunol 155: 5029-5037, 1995.

47. Botella-Estrada R, Escudero M, O'Connor JE, et al: Cytokine production by peripheral lymphocytes in melanoma. Eur Cytokine Netw 16: 47-55, 2005

48. Elsasser-Beile U, von Kleist S, Stahle W, SchurhammerFuhrmann C, Monting JS and Gallati H: Cytokine levels in whole blood cell cultures as parameters of the cellular immunologic activity in patients with malignant melanoma and basal cell carcinoma. Cancer 71: 231-236, 1993.

49. Pellegrini P, Berghella AM, Del Beato T, Cicia S, Adorno D and Casciani CU: Disregulation in TH1 and TH2 subsets of $\mathrm{CD} 4^{+} \mathrm{T}$ cells in peripheral blood of colorectal cancer patients and involvement in cancer establishment and progression. Cancer Immunol Immunother 42: 1-8, 1996

50. Filella X, Alcover J, Zarco MA, Beardo P, Molina R and Ballesta AM: Analysis of type T1 and T2 cytokines in patients with prostate cancer. Prostate 44: 271-274, 2000.

51. Argiles JM, Busquets S and Lopez-Soriano FJ: The pivotal role of cytokines in muscle wasting during cancer. Int J Biochem Cell Biol 37: 2036-2046, 2005.

52. Wanebo HJ, Jones T, Pace R, Cantrell R and Levine P. Immune restoration with interleukin-2 in patients with squamous cell carcinoma of the head and neck. Am J Surg 158: 356-360, 1989.

53. Farinas MC, Rodriguez-Valverde V, Zarrabeitia MT, Parra-Blanco JA and Sanz-Ortiz J: Contribution of monocytes to the decreased lymphoproliferative response to phytohemag-glutinin in patients with lung cancer. Cancer 68: 1279-1284, 1991

54. Boussiotis VA, Tsai EY, Yunis EJ, et al: IL-10-producing T cells suppress immune responses in anergic tuberculosis patients. J Clin Invest 105: 1317-1325, 2000.

55. Brunetti M, Colasante A, Mascetra N, Piantelli M, Musiani P and Aiello FB: IL-10 synergizes with dexamethasone in inhibiting human T cell proliferation. J Pharmacol Exp Ther 285: 915-919, 1998.

56. Roth MJ, Qiao YL, Abnet CC, et al: Cellular immune response is not associated with incident cancer or total mortality: a prospective follow-up. Eur J Cancer Prev 15: 548-550, 2006.

57. Carson PJ, Nichol KL, O'Brien J, Hilo P and Janoff EN: Immune function and vaccine responses in healthy advanced elderly patients. Arch Intern Med 160: 2017-2024, 2000.

58. Wolf AM, Wolf D, Steurer M, Gastl G, Gunsilius E and Grubeck-Loebenstein B: Increase of regulatory T cells in the peripheral blood of cancer patients. Clin Cancer Res 9: 606-612, 2003.

59. Liyanage UK, Moore TT, Joo HG, et al: Prevalence of regulatory T cells is increased in peripheral blood and tumor microenvironment of patients with pancreas or breast adenocarcinoma. J Immunol 169: 2756-2761, 2002.

60. Marshall NA, Christie LE, Munro LR, et al: Immunosuppressive regulatory $\mathrm{T}$ cells are abundant in the reactive lym-phocytes of Hodgkin lymphoma. Blood 103: 1755-1762, 2004.

61. Curiel TJ, Coukos G, Zou L, et al: Specific recruitment of regulatory $\mathrm{T}$ cells in ovarian carcinoma fosters immune privilege and predicts reduced survival. Nat Med 10: 942-949, 2004

62. Pisani RJ: Bronchogenic carcinoma: immunologic aspects. Mayo Clin Proc 68: 386-392, 1993.

63. Reichert TE, Scheuer C, Day R, Wagner W and Whiteside TL: The number of intratumoral dendritic cells and zeta-chain expression in $\mathrm{T}$ cells as prognostic and survival biomarkers in patients with oral carcinoma. Cancer 91: 2136-2147, 2001

64. Ruffini E, Asioli S, Filosso PL, et al: Clinical significance of tumor-infiltrating lymphocytes in lung neoplasms. Ann Thorac Surg 87: 365-371, 2009.

65. Yannelli JR, Hyatt C, McConnell S, et al: Growth of tumorinfiltrating lymphocytes from human solid cancers: summary of a 5-year experience. Int J Cancer 65: 413-421, 1996.

66. Bellone G, Turletti A, Artusio E, et al: Tumor-associated transforming growth factor-beta and interleukin-10 contribute to a systemic Th2 immune phenotype in pancreatic carcinoma patients. Am J Pathol 155: 537-547, 1999. 
67. Ruttinger D, van den Engel NK, Winter H, et al: Adjuvant therapeutic vaccination in patients with non-small cell lung cancer made lymphopenic and reconstituted with autologous PBMC: first clinical experience and evidence of an immune response. J Transl Med 5: 43, 2007.

68. Ito $\mathrm{N}$, Nakamura $\mathrm{H}$, Metsugi $\mathrm{H}$ and Ohgi S: Dissociation between $\mathrm{T}$ helper type 1 and type 2 differentiation and cytokine production in tumor-infiltrating lymphocytes in patients with lung cancer. Surg Today 31: 390-394, 2001.

69. Ortegel JW, Staren ED, Faber LP, Warren WH and Braun DP Cytokine biosynthesis by tumor-infiltrating T lymphocytes from human non-small-cell lung carcinoma. Cancer Immunol Immunother 48: 627-634, 2000.

70. Ramos TC, Vinageras EN, Ferrer MC, et al: Treatment of NSCLC patients with an EGF-based cancer vaccine: report of a phase I trial. Cancer Biol Ther 5: 145-149, 2006.

71. Salgia R, Lynch T, Skarin A, et al: Vaccination with irradiated autologous tumor cells engineered to secrete granulocytemacrophage colony-stimulating factor augments antitumor immunity in some patients with metastatic non-small-cell lung carcinoma. J Clin Oncol 21: 624-630, 2003.
72. Sutmuller RP, van Duivenvoorde LM, van Elsas A, et al: Synergism of cytotoxic T lymphocyte-associated antigen 4 blockade and depletion of CD25(+) regulatory T cells in anti-tumor therapy reveals alternative pathways for suppression of autoreactive cytotoxic T lymphocyte responses. J Exp Med 194: 823-832, 2001.

73. Furuichi Y, Tokuyama H, Ueha S, Kurachi M, Moriyasu F and Kakimi K: Depletion of $\mathrm{CD} 25^{+} \mathrm{CD} 4^{+} \mathrm{T}$ cells (Tregs) enhances the $\mathrm{HBV}$-specific $\mathrm{CD} 8^{+} \mathrm{T}$ cell response primed by DNA immunization. World J Gastroenterol 11: 3772-3777, 2005.

74. Dudley ME, Wunderlich JR, Yang JC, et al: Adoptive cell transfer therapy following non-myeloablative but lymphodepleting chemotherapy for the treatment of patients with refractory metastatic melanoma. J Clin Oncol 23: 2346-2357, 2005. 